\title{
Web-Face-to-Face Mixed-Mode Design in a Longitudinal Survey: Effects on Participation Rates, Sample Composition, and Costs
}

\author{
Annamaria Bianchi ${ }^{1}$, Silvia Biffignandi ${ }^{1}$, and Peter Lynn ${ }^{2}$
}

\begin{abstract}
Sequential mixed-mode designs are increasingly considered as an alternative to intervieweradministered data collection, allowing researchers to take advantage of the benefits of each mode. We assess the effects of the introduction of a sequential web-face-to-face mixed-mode design over three waves of a longitudinal survey in which members were previously interviewed face-to-face. Findings are reported from a large-scale randomised experiment carried out on the UK Household Longitudinal Study. No differences are found between the mixed-mode design and face-to-face design in terms of cumulative response rates and only minimal differences in terms of sample composition. On the other hand, potential cost savings are evident.
\end{abstract}

Key words: Attrition; total survey error; nonresponse bias; randomised experiment.

\section{Introduction}

Combining different modes within a survey has long been thought to provide opportunities to benefit from the strength of each mode (de Leeuw 2005). Biemer and Lyberg (2003) assert that in United States and Western Europe mixing modes is the norm for surveys at present. Since the development of web surveys, mixed-mode data collection methods with a web component are increasingly considered as an efficient possibility by many organisations. Indeed, the inclusion of web into a mixed-mode design has potentials to reduce costs, increase timeliness, and improve quality/sample composition (Groves and Lyberg 2010; Couper 2011; Kreuter 2013).

The opportunities for mixed-mode data collection with web are particularly appealing for longitudinal surveys. Indeed, some of the constraints on implementing mixed-mode surveys are reduced in the longitudinal setting, thanks to the diversity of information that can be collected from sample members at the recruitment/first wave. First, collection of

${ }^{1}$ Department of Management, Economics and Quantitative Methods, University of Bergamo, via dei Caniana 2, 24127 Bergamo, Italy. Emails: annamaria.bianchi@unibg.it, silvia.biffignandi@unibg.it

${ }_{2}^{2}$ Institute for Social and Economic Research, University of Essex, Wivenhoe Park, Colchester, Essex C04 3SQ, UK. Email: plynn@essex.ac.uk

Acknowledgments: The first two authors would like to acknowledge support by the COST Action IS1004 and by the ex $60 \%$ University of Bergamo, Biffignandi grant. The contribution of the third author forms part of the methodological research programme of Understanding Society: the UK Household Longitudinal Study. Understanding Society is funded by the (UK) Economic and Social Research Council and various Government Departments, with scientific leadership by the Institute for Social and Economic Research, University of Essex, and survey delivery by NatCen Social Research and Kantar Public. The research data are distributed by the UK Data Service. The authors thank Dr. Annette Jäckle for providing Stata codes. 
contact information for sample members permit gains and cost savings to be made by approaching panel members in the most cost-efficient mode. For example, email addresses can be collected at the first wave to facilitate subsequent invitations to complete web surveys. Second, knowledge about which sample members are more or less likely to respond in which mode allows targeting of particular mode strategies at specific subgroups, in the framework of adaptive survey design (Lynn 2014; Calinescu and Schouten 2015; Bianchi and Biffignandi 2014). Finally, the study of the effects of different mode strategies can take advantage of the wide range of information available for each sample member from previous waves, thus providing a rather unique opportunity to identify detailed characteristics of respondents in different modes.

Some other considerations in the introduction of mixed-mode designs are also specific to the longitudinal context. First, high response rates are essential to allow longitudinal analyses (Lynn forthcoming). This is because nonresponding sample members cannot be replaced by new sample members. Thus, response rates and cumulative response rates are more important in the longitudinal framework than in cross-sectional surveys. Second, in an ongoing panel that has previously been interviewer-administered, sample members have prior experience of the interview in another mode and prior knowledge of the survey content. These prior experiences might increase the chances of response in web mode, even in the absence of an interviewer (Jäckle et al. 2015), as the task of introducing the survey and the respondent task is greatly reduced.

The aim of this article is to study the effect of a mixed-mode design including web on several aspects related to data quality in a longitudinal survey. By 'mixed-mode' we refer specifically to a sequential mixed-mode design, where web is offered first, followed by face-to-face follow-up of nonrespondents to the web phase. We compare this mixed-mode design to a simple face-to-face design. In both designs we allow the possible use of different modes in a final 'mop-up' step to boost response (e.g., Computer Assisted Telephone Interviewing (CATI)) as we believe this represents good practice and does not fundamentally affect the nature of the designs. Details of the specific designs upon which our analyses are based are presented below. To the best of our knowledge, this is the first study of the effects of introducing a mixed-mode design including web over multiple waves of a longitudinal survey.

Several issues may arise when using web and mixed-modes for data collection. Participation rates are usually low for web surveys (Fan and Yan 2010). Cooperation may be harder to maintain in the absence of personal interviewer contact. This may particularly be the case when the mixed-mode design uses a lower response rate mode first in a sequential design (Lynn 2013). However, the effect on response rates of including web in a mixedmode design is not completely clear. Several studies have found a lower response rate with a sequential mixed-mode design including web than with the equivalent design without web (Griffin et al. 2001; Janssen 2006; Lagerstrøm 2008; Leesti 2010; Martin and Lynn 2011; Souren 2012), while others have found that adding web to an otherwise single-mode design does not affect response rate (Fong and Williams 2011; Klausch et al. 2015a).

Jäckle et al. (2015) report on the effects at one wave only with reference to the same experiment we analyse. They found that individual response rates were lower with the mixed-mode design and no subgroup could be identified where the reverse was true. They also found that the mixed-mode design resulted in a lower proportion of households in 
which all individuals responded. Gaia (2014) found no significant difference in attrition rates after three waves between the two designs.

The possibility of differential measurement error is a very important concern when considering converting a single-mode interviewer-administered survey to a mixed-mode survey including web. Several studies have identified systematic differences in measurement between modes (Bowling 2005) and in some contexts this has been shown to result in measurement differences between face-to-face single-mode and webface-to-face mixed-mode data collection (Jäckle 2016; Klausch et al. 2015b). However, effects on measurement are not the focus of this article.

In the longitudinal context, response behavior may be affected by the time sample members have been in the panel and by previous wave outcome. It is well known that waveon-wave attrition rates in longitudinal studies are highest at the second wave and then decline over time (Lugtig 2014; Schoeni et al. 2013; Uhrig 2008). There is also evidence that the correlates of nonresponse may change over waves of a survey (Farrant and O'Muircheartaigh 1991). Further, a study based on four waves of the UK Household Longitudinal Study found that changes in correlates of nonresponse at each subsequent wave are lower compared to the previous one (Bianchi and Biffignandi 2017). Also, those who have been longer in the panel have more experience of the interview in another mode and prior knowledge of the survey content than those who have entered the panel more recently. These aspects might increase the chance of a successful transition to web interviewing.

It is thus expected that more recent panel members will show higher levels of attrition/nonresponse. Jäckle et al. (2015) found that for longer panel members (original sample) the proportion of interviews of any form was lower with mixed-mode, while there was no difference by mode treatment for more recent panel entrants (refreshment sample).

Previous wave nonrespondents are known to have lower response propensities in subsequent waves (Watson and Wooden 2014; Jäckle et al. 2015). We thus expect higher attrition rates among previous wave nonrespondents, which could result in greater sensitivity to mode treatment amongst this group. Furthermore, an invitation to complete the interview by web offers the opportunity to at least make contact with some sample members who are very hard to contact face-to-face (due to being rarely at home at the times when interviewers visit). Jäckle et al. (2015) found that amongst previous wave respondents the mixed-mode design resulted in a higher proportion of refusals than faceto-face design and amongst previous wave nonrespondents it resulted in a smaller proportion of proxy interviews. Moreover, Jäckle et al. (2015) found several groups to be less likely to give an interview in the mixed-mode treatment than face-to-face: men, white, in rural location, web users, those for whom an email address was available, age 21-30, in a household with children, and individuals who said they would definitely not do the survey by web. If these patterns persist over waves, then they are expected to lead to biases in the estimates of correlated variables. Persistent patterns could guide the implementation of targeted mode assignment.

Thus, our first research question is:

RQ1: Does the mixed-mode design affect participation rates (cumulatively or at each wave separately), either overall or amongst important subgroups, compared to the primarily face-to-face design? 
Furthermore, it is possible that subgroup differences in response propensity could differ between modes (Groves and Peytcheva 2008; Voogt and Saris 2005). Heterogeneity across modes in response propensities could result in smaller compositional biases with mixed-mode designs than with single-mode designs. Empirical knowledge on these aspects is rather limited, especially in the context of longitudinal surveys. Voorpostel and Ryser (2011) in the implementation of a web-face-to-face concurrent mixed-mode design for refusal conversion in an otherwise CATI panel survey (the Swiss Household Panel) found that the group that completed the web questionnaire tended to have characteristics that were slightly different from the CATI group. They argue that, if larger numbers had been reached, this would have diminished the bias in demographic characteristics. No significant differences in sample composition between a sequential mixed-mode design and single-mode face-to-face were found by Lynn (2013), with respect to a CATI-face-toface design in the UK, or by Klausch et al. (2015a), with respect to CATI-face-to-face, web-face-to-face or mail-face-to-face. The relevance of sample composition measures depend on the substantive analytical objectives of data users. In case of multi-purpose surveys with many users and many equally-important estimates, it is essential that the response set presents no compositional biases with respect to many variables. Our second research question is therefore:

RQ2: Does the mixed-mode design affect sample composition, compared to the primarily face-to-face design? Does any such effect change over waves as attrition cumulates?

Since one of the main reasons for the implementation of mixed-mode designs with a web component is related to cost reduction, we investigate some aspects related to survey costs. First, in the context of household panels where all household members need to be interviewed, a significant cost-saving may be obtained only when all household members respond by web, as this avoids the need for an interviewer to visit the household in the face-to-face follow-up phase. In this respect and with reference to one wave only, Jäckle et al. (2015) found that one in five households fully responded online, suggesting the potential for useful cost savings. We extend the results in Jäckle et al. (2015) by investigating the extent to which households fully respond online over three waves in order to ascertain whether cost savings may increase over time following the introduction of a mixed-mode design. Further, we explicitly evaluate the relative mean field cost per issued household for the mixed-mode design and the primarily face-to-face design and for each wave. In this respect our analysis goes beyond that in Jäckle et al. (2015). So our third research question is:

RQ3: To what extent does the mixed-mode design reduce field work costs over waves, compared to the primarily face-to-face design?

We analyse data from the Understanding Society Innovation Panel. The Innovation Panel is a longitudinal panel designed explicitly to enable methodological research. The size of the panel is large, which provides good statistical power. The survey aims to interview each adult member of the household. At Wave 5, a randomised experiment was carried out, to inform decisions on whether and how the main Understanding Society Survey (Buck and McFall 2012) might move from a single-mode face-to-face survey to a 
mixed-mode survey that includes web interviewing. Two-thirds of sample units were allocated at random to the mixed-mode treatment (sequential mixed-mode in which web was followed by face-to-face), with the other one-third receiving the face-to-face treatment. At the time of the experiment, the panel consisted of 1,573 households and 3,040 adults eligible for interview. The experiment continued at Waves 6 and 7, so that respondents received the same treatment they were assigned to at Wave 5. This structure of the experiment enables investigation of long term effects of mode treatments on panel attrition. Minor changes to the design were applied at Waves 6 and 7, with reference to incentive levels and follow-up procedures. Particularly, at the end of the fieldwork a final 'mop-up' phase was included, which introduced CATI and web options in the face-to-face treatment and CATI in the mixed-mode treatment. Thus, in Waves 6 and 7 the face-to-face treatment was not strictly single-mode. However, as modes used in the 'mop-up' stage played a very small part in overall response (see Subsection 2.1 below), we will use the term 'primarily face-to-face' for the face-to-face treatment in Waves 6 and 7.

Positive effects of incentives on response rates have been found for web surveys (Göritz 2006, 2010, 2015). Incentives have found to be effective also in longitudinal surveys (Laurie and Lynn 2009; Jäckle and Lynn 2008). Thus, respondent incentives were provided in both treatment groups, though the level and nature of the incentives differed between the groups, reflecting the reality that sample members might require additional motivation in the absence of an interviewer. Each of the two mode treatments therefore represents a realistic overall design, though it must be taken into account that the unit cost of incentives is slightly higher in the mixed-mode treatment. Details of the incentive strategies are set out in Section 2 below and a cost comparison is presented in Section 6 .

In a Total Survey Error (TSE) perspective (Biemer 2010; Groves and Lyberg 2010; Lynn and Lugtig 2017), this article represents a step towards the optimisation of surveys by maximising certain aspects of survey quality within a budgetary constraint. For example, if cost savings are found by the introduction of mixed-mode with a web component, a larger sample could be afforded for the same budget, which in turns leads to lower variance of the estimates.

In the next section of the article, we describe the data and the experimental study. Next, we present results on participation (Section 3), sample composition (Section 4), and costs (Section 5). Sections 6 and 7 conclude.

\section{Data}

We use data from the Understanding Society Innovation Panel (Uhrig 2011). More precisely, we consider data from a randomised experiment carried out at Wave 5 and continued at Waves 6 and 7. Subsection 2.1 describes the main characteristics of the panel, Subsection 2.2 provides details on the experimental design.

\subsection{The Understanding Society Innovation Panel}

The Understanding Society Innovation Panel is an ongoing longitudinal survey which has collected data in annual waves since 2008 (Lynn and Jäckle, forthcoming). The target population for the Innovation Panel is all individuals aged 16 or over and living in 
England, Scotland, or Wales. The sample had two components: those who were invited to take part at each wave since Wave 1 and those who entered the survey at Wave 4 . We refer to these two sample components as the original sample and the refreshment sample, respectively. Another refreshment sample was added in Wave 7, but is excluded from our analyses.

Both samples are stratified, clustered, probability samples of persons. Primary sampling units are postal sectors, secondary sampling units are residential addresses selected from the Postcode Address File (Lynn and Lievesley 1991) and sample elements are persons. The sample of persons is therefore initially clustered within households (though that clustering reduces over waves of the panel). Further details on the Innovation Panel sample design can be found in Lynn (2009).

The Understanding Society Innovation Panel involves interviews at twelve-month intervals with the initial sample members and all members of the current household of each sample person. Household response at any wave can thus be complete if all household members answer the survey or partial, if only some of the household members participate. Only sample members who were in participating households at the first wave for that sample were re-approached for interview at subsequent waves. Sample members were followed to their new location if they moved anywhere within Great Britain. From Wave 2 onwards, nonresponse at one wave did not preclude an interview attempt at the next wave. Households in which no person responded at two successive waves are no longer issued to the field. Thus, in the sample issued to the field at Wave 5 - which forms the base for most of our analyses - the original sample included all individuals who were in households that had responded at either Wave 3 or Wave 4 and the refreshment sample only included individuals in households that had responded at Wave 4. Thus, at Wave 5 it is only the original sample that includes previous wave nonrespondents.

Interviews cover a wide range of topics, such as household dynamics, economic activity, income, health, housing, and political attitudes. The survey is a multi-purpose survey intended as a major research resource, with thousands of users from different disciplines and a very diverse range of analytical objectives (Buck and McFall 2012).

Proxy interviews are allowed on behalf of individuals who cannot be interviewed in person, but only after considerable efforts have been made to obtain a personal interview. The decision to allow a proxy interview is made subjectively on a case-by-case basis by field staff. At Waves 5, 6, and 7 - the field outcomes which are the subject of our analyses - the proportion of interviews completed by proxy was $6.9 \%, 5.9 \%$, and $3.2 \%$, respectively. As for modes used in data collection, at Waves 1, 3, and 4, all interviews were carried out face-to-face. Experimentation with a mixture of face-to-face and CATI was carried out at Wave 2 in 2009 (Lynn et al. 2010). The main conclusion from that experiment was that a CATI-face-to-face sequential mixed-modes design, if implemented in a way that would save costs, was likely to result in lower response rates (Lynn 2013). For that reason, CATI was not included as an initial mode at Waves 5 to 7.

\subsection{Experimental Design}

At Wave 5, all sample members were randomly allocated to one of two treatment groups. The allocation was at the household level, so all individuals in the same household 
received the same treatment. Interviewers are assigned to households based on geographic location, a factor that had no influence on the allocation to treatment, so each interviewer assignment included households in both treatment groups. One third of the sample was allocated to the primarily face-to-face treatment and two thirds were allocated to the webface-to-face sequential mixed-mode design. The experiment was continued (with the same treatment allocation) at Waves 6 and 7. The distribution of the issued sample of households across samples and mode treatments is summarised in Table 1.

In Wave 5, the face-to-face treatment involved standard Understanding Society procedures. Each adult sample member (aged 16 or over) was sent an advance letter with a prepaid unconditional incentive, after which interviewers visited to attempt face-to-face interviews. In each household, one person was asked to complete the household enumeration grid and the household questionnaire. All household members aged 16 or over were asked for an individual interview, including a self-completion component administered by computer-assisted self-interviewing (CASI).

In the mixed-mode treatment group, sample members aged 16 or over were sent a letter with a prepaid unconditional incentive, inviting them to take part by web. The letter included the URL and a unique user ID, which was to be entered on the welcome screen. A version of the letter was additionally sent by email to all sample members for whom an email address was available (around half of the sample: of the emails sent, $10 \%$ bounced, $30 \%$ were opened by the recipient and $60 \%$ were left unopened). For people who had indicated at previous waves that they do not use the internet regularly for personal use, the letter mentioned that they would also have the opportunity to do the survey with an interviewer. Up to two email reminders were sent at three-day intervals. Sample members who had not completed the web interview after two weeks were sent a reminder by post and interviewers then started visiting them to carry out face-to-face interviews. The interviewer visits began in the same week that the reminder letter would have been received. Face-to-face interviewers thereby had their full allocation at the start of their fieldwork, rather than having nonresponding web individuals being passed to them during the fieldwork period. The web survey remained open throughout the fieldwork period.

The first household member to log on to do the web survey was asked to complete the household grid, which collects information on who is currently living in the household. The web grid included an additional question to identify who is responsible for paying bills. The household questionnaire could be completed by either this person or their spouse/partner. For these sample members the household questionnaire was displayed first, then leading on to the individual questionnaire. Once one partner had completed the household questionnaire, it would not appear for the other partner. The web questionnaire was based on the face-to-face one, with some adaptations, for example incorporating interviewer instructions into question wording, removing references to showcards, and making 'help' screens more respondent-appropriate. There were no differences in questionnaire content, question order or routing. The web survey was not suitable for completion using a small mobile device. If a mobile device was used to access the log-on page, the respondent was automatically directed to a page requesting that they log on from a computer.

The same procedures were carried out in Waves 6 and 7, with a few small differences. First, respondents accessing the survey from a mobile device were no longer blocked from completing it, though they were still presented with a warning message suggesting that it 


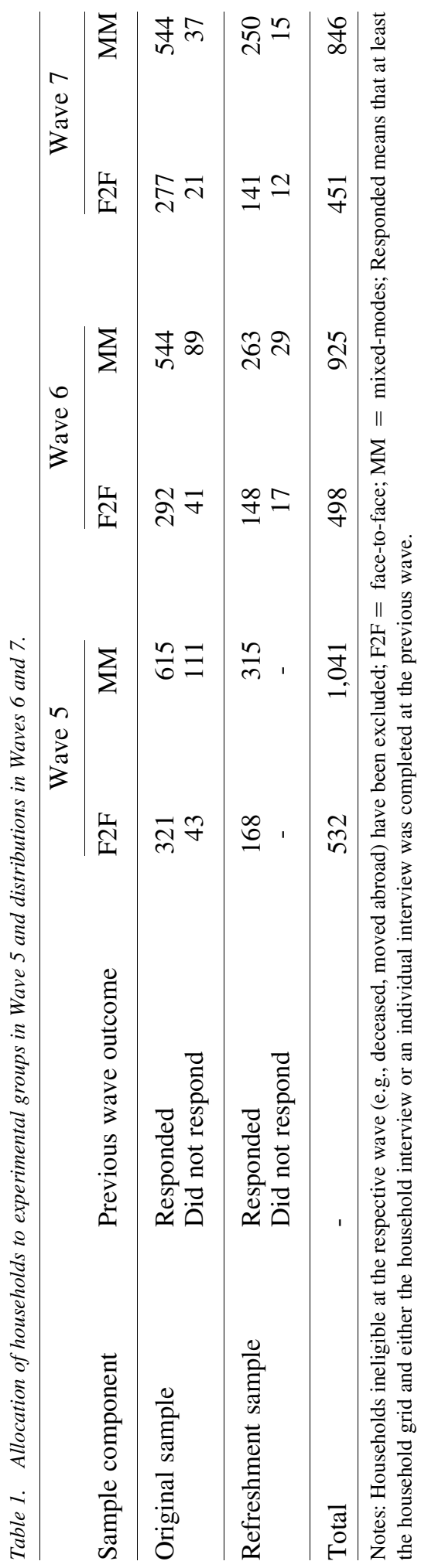


would be easier to complete the survey on a PC or laptop. In the mixed-mode treatment group, the proportion of individual web interviews completed on a mobile device was $7 \%$ at Wave 6 and $18 \%$ at Wave 7 . Second, the proportion of sample members in the mixedmode treatment who had supplied a valid email address and could therefore be sent a survey invitation by email increased at each wave, being around 60\% at Wave 6 and $65 \%$ at Wave 7. Third, "nonresponse mop-up" procedures to obtain participation of individuals who had not participated by the end of the fieldwork period were extended to include additional modes. This included nonresponding individuals in partially responding households. Nonrespondents in the face-to-face group were sent a letter offering the opportunity to participate by web. The letter included the URL of the web instrument and a unique log-on code. For those whose email addresses were available, this invitation was also sent by email. A few days later, an interviewer attempted contact by telephone with all those for whom a phone number was known in order to remind them of the web questionnaire, and to administer a CATI interview if possible. Telephone contacts were also attempted with all remaining nonrespondents in the mixed-mode group. The telephone interviewer reminded the sample member that they could participate on the web, but was also able to administer the interview by CATI. Cases for which a telephone number was not known were not contacted again at this stage. CATI was included in this final stage at Waves 6 and 7 on the grounds that an additional contact mode might increase the chances of contact being made with some of the most difficult to contact sample members. At Wave 6, just five individual interviews ( $0.7 \%$ of all interviews) in the face-toface treatment group were completed by CATI and fifteen $(2.2 \%)$ by web. In the mixedmode group, fourteen interviews (1.0\%) were completed by CATI. At Wave 7, just one individual interview $(0.1 \%$ of all interviews) in the face-to-face treatment group was completed by CATI and $25(3.2 \%)$ by web. In the mixed-mode group, three interviews $(0.2 \%)$ were completed by CATI. It is clear that these additional modes had only a minor impact on response outcomes.

At each wave all sample members received an unconditional incentive, enclosed with the advance letter. The value of the incentive was manipulated as part of a separate experiment. Allocation was at the household level, so all individuals in the same household received the same incentive. At Wave 5, in both mode treatment groups original sample members received either GBP 5 or GBP 10, while refreshment sample members received GBP 10, GBP 20, or GBP 30. Additionally, a conditional incentive experiment was carried out within the mixed-mode group (fully crossed with the unconditional incentive experiment) to test ways of increasing web participation. Half of the households were offered an additional incentive of GBP 5 per person conditional on all eligible household members completing the web survey within two weeks. This was mentioned in the advance letters to all household members in this treatment group. Detailed analyses of the impact of incentives at Wave 5 are presented in Bianchi and Biffignandi (forthcoming).

At Wave 6, the incentive experiment was restricted to the mixed-mode part of the sample. Individuals were allocated in equal proportions to three treatments: GBP 10 unconditional incentive, GBP 30 unconditional, or GBP 10 unconditional incentive with an additional GBP 20 per individual conditional on all adult household members taking part online within the two-week web-only period. For the primarily face-to-face part of the sample, all sample members were provided a GBP 10 incentive. 
At Wave 7, all continuing sample (original and Wave 4 refreshment) members were again administered the same incentive as at Wave 6.

The analyses carried out in Sections 3 and 4 are on households and individuals aged 16 or over. For households, analyses are restricted to households issued to the field at the respective wave, excluding ineligible households at that wave. For Wave 7, households from the Wave 7 refreshment sample are also excluded. Sample sizes are 1,573 for Wave 5, 1,423 for Wave 6, and 1,297 for Wave 7. As for individuals, we restricted to individuals issued to the field at Wave 5 and eligible at Waves 5, 6, and 7 - counting individuals not issued to later waves as (eligible) nonrespondents (any household that did not respond at either wave $w-1$ or $w$ would not be issued at $w+1)$. For those individuals issued to Wave 5 and not issued to later waves, nonresponse is classified using last wave available nonresponse classification. The sample size is 2,756. For individuals, we use variables from the most recent available interview as covariates. The cost analysis in Section 5 is based on all households issued to field.

As mentioned above, Jäckle et al. (2015) perform similar analyses as ours, but using only Wave 5 data. With respect to the samples used in Jäckle et al. (2015), we consider the same sample for households at Wave 5. The sample of individuals is not the same as we consider individuals eligible over Waves 5, 6, and 7 (not 5 only). As a consequence, results for households at Wave 5 (first three columns of Table 5) are consistent with those in Jäckle et al. (2015), while results for individuals at Wave 5 are not exactly the same.

\section{Participation}

The first aspect that we consider is the impact of mixed-mode data collection on participation (RQ1). Notice that all our analyses are conditional on being issued to the field at Wave 5, which means that all Wave 1 nonresponding households and some who adamantly refused or were persistent nonrespondents at Waves 2 to 4 , have been dropped from the sample. Our focus is on the effect of mode treatment on attrition at Waves 5, 6, and 7, the waves at which the randomised experiment was carried out. In Subsection 3.1, we consider individual participation, while in Subsection 3.2 we investigate household participation, as interest lies also in how any differences in individual participation cluster within households.

\subsection{Individual Participation}

A particularly important outcome in the context of longitudinal studies is the cumulative response rate over waves, as this is related to the possibility of performing longitudinal analyses. For analyses of change, observations need to be available from each wave of interest and different patterns of missingness across waves may lead to a large number of cases being dropped from the analyses.

Table 2 compares mixed-mode data collection with primarily face-to-face data collection in terms of the number of waves (out of three) at which the sample member provides a full interview, as well as full interview response rate in each wave separately. No significant differences are found between treatments for the cumulative response rate over three waves $(P=0.45)$. Looking at response in each wave separately, the effect of 
Table 2. Individual response rates (in $\%)-F 2 F=$ face-to-face; $M M=$ mixed-modes; $P$-values from Pearson $\chi^{2}$ tests, corrected for the survey design (strata and clusters).

\begin{tabular}{lccc}
\hline Response & F2F & MM & $P$ \\
\hline Waves 5-7 response & & & \\
$\quad$ 3 full interviews & 47.3 & 49.1 & 0.45 \\
2 or 1 full interviews & 32.9 & 19.6 & 0.57 \\
0 full interviews & 19.8 & 68.4 & 0.92 \\
\hline Wave 5 full interview & 71.0 & 70.7 & 0.30 \\
\hline Wave 6 full interview & 69.3 & 59.1 & 0.52 \\
\hline Wave 7 full interview & 56.1 & 0.21 \\
\hline$N$ & 940 & 1,816 & \\
\hline
\end{tabular}

mixed-modes on the proportion of full interviews went from -2.6 percentage points at Wave 5 to +3.0 at Wave 7 , though none of these differences are statistically significant.

Turning to individual response by subgroups of interest (Table 3), no difference between the mixed-mode design and primarily face-to-face design was observed with respect to the cumulative response rate, in the original sample $(P=0.86)$, the refreshment sample $(P=0.30)$, the original sample Wave 4 respondents $(P=0.81)$, or the original sample Wave 4 nonrespondents $(P=0.11)$. Amongst Wave 4 nonrespondents in the original sample, the mixed-mode design resulted in a lower proportion of no interview over three waves than face-to-face $(54.9 \%$ vs $66.5 \%, P=0.09)$. Separate analyses for each wave show that the proportion of full interviews did not differ significantly between treatments for either the original sample $(P=0.16)$ or the refreshment sample $(P=0.67)$ in Wave 5. In Waves 6 and 7, amongst Wave 4 nonrespondents in the original sample, the mixed-mode design resulted in a higher proportion of full interviews than face-to-face design (32.9\% vs $20.0 \%, P=0.06$ in Wave 6 and $28.0 \%$ vs. $18.7 \%, P=0.08$ in Wave 7 ). In Wave 7, the proportion of full interviews is higher for the mixed-mode group for both the original and the refreshment samples, even though the differences did not reach statistical significance.

To investigate whether the mixed-mode design had different effects on attrition for different subgroup characteristics, we fitted a logit model predicting full response over three waves (versus proxy or nonresponse in any one of the three waves) using individual characteristics and interactions of those characteristics with treatment as predictors. Individual characteristics were measured in Wave 4 (or last available interview before Wave 5). Results for the original responding sample are summarised in Table 4, which shows the estimated coefficients from the model, together with $p$-values of t-tests for significance (adjusted for sample design). At the five percent level, the only significant interaction is between mode and web preference, with respondents who said at Wave 4 that they would definitely/maybe respond to a web survey having higher probabilities to respond in the mixed-mode group. The effect is stronger for those who declared they would definitely respond to a web survey. 


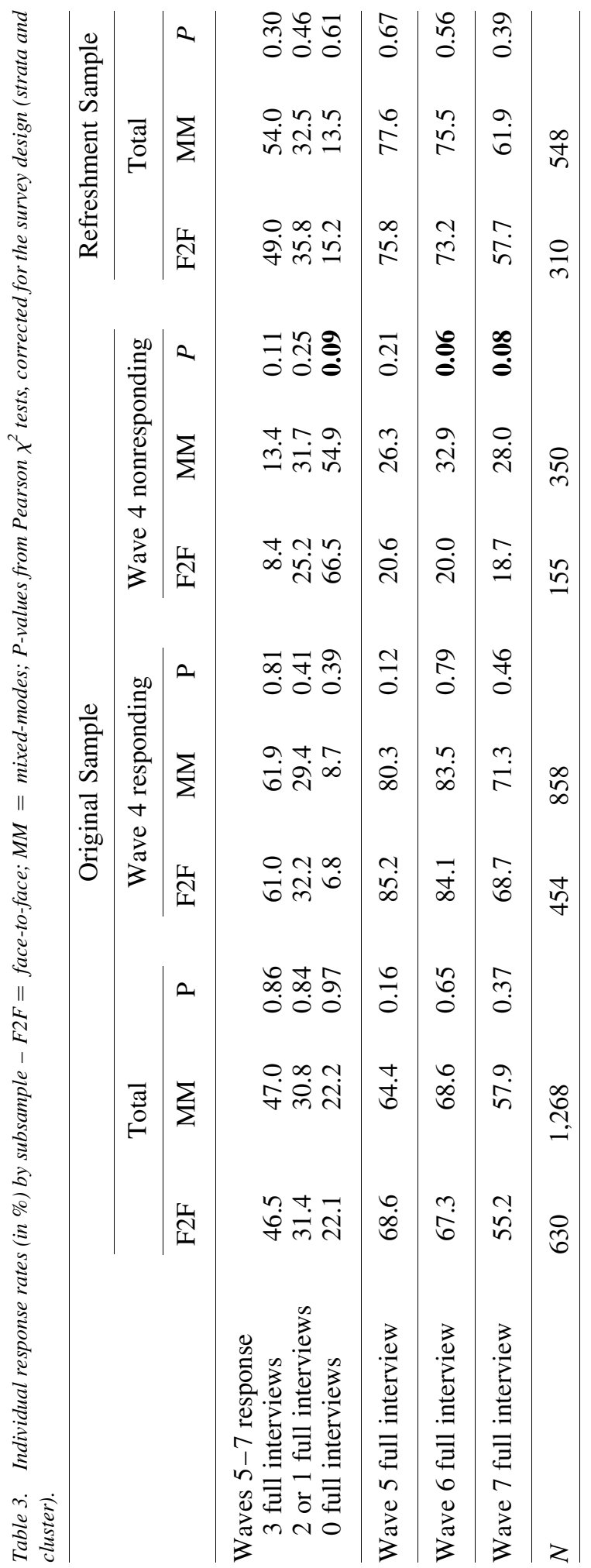


Table 4. Logistic regression results for giving full interview in Waves 5, 6, and 7 - Original sample (Wave 4 respondents only), $N=1,296$ - based on a logit model including the allocated mode, characteristics of the sample members, and interactions between the mode and characteristics as predictors.

\begin{tabular}{|c|c|c|c|c|}
\hline Variable & Category & Coefficient & Std. Error & $P$-value \\
\hline Intercept & - & -1.01 & 0.65 & 0.13 \\
\hline $\begin{array}{l}\text { Mixed-Mode (MM) } \\
\text { (Ref. Face-to-face goup) }\end{array}$ & Mixed-mode group & 0.33 & 0.82 & 0.69 \\
\hline $\begin{array}{l}\text { Gender } \\
\text { (Ref. Female) }\end{array}$ & Male & -0.05 & 0.18 & 0.78 \\
\hline $\begin{array}{l}\text { Race } \\
\text { (Ref. Nonwhite) }\end{array}$ & White & 0.76 & 0.48 & 0.12 \\
\hline $\begin{array}{l}\text { Working Status } \\
\text { (Ref. Not in work) }\end{array}$ & In work & 0.03 & 0.28 & 0.93 \\
\hline $\begin{array}{l}\text { Urbanicity } \\
\text { (Ref. Rural) }\end{array}$ & Urban & 0.41 & 0.29 & 0.16 \\
\hline $\begin{array}{l}\text { Webuser } \\
\text { (Ref. No) }\end{array}$ & Yes & 0.08 & 0.33 & 0.80 \\
\hline $\begin{array}{l}\text { Email given } \\
\text { (Ref. No) }\end{array}$ & Yes & 0.52 & 0.28 & 0.06 \\
\hline Age & $16-20$ & -0.79 & 0.53 & 0.14 \\
\hline \multirow[t]{5}{*}{ (Ref. $41-50)$} & $21-30$ & -0.63 & 0.49 & 0.21 \\
\hline & $31-40$ & 0.31 & 0.34 & 0.36 \\
\hline & $51-60$ & 0.38 & 0.36 & 0.29 \\
\hline & $61-70$ & 1.52 & 0.45 & 0.00 \\
\hline & $71+$ & 0.20 & 0.49 & 0.68 \\
\hline Household type & Single & 0.19 & 0.34 & 0.58 \\
\hline \multirow[t]{4}{*}{ (Ref. Couple) } & Single, children & -0.23 & 0.57 & 0.69 \\
\hline & Couple, children & 0.22 & 0.42 & 0.60 \\
\hline & $2+$ unrelated adults & -0.08 & 0.44 & 0.86 \\
\hline & $\begin{array}{l}2+\text { unrelated adults, } \\
\text { children }\end{array}$ & 0.14 & 0.42 & 0.75 \\
\hline Web preference & Maybe & -0.42 & 0.33 & 0.20 \\
\hline$(\operatorname{Ref.} \mathrm{No})$ & Yes & -0.57 & 0.38 & 0.14 \\
\hline MM\#Gender & MM\#Male & -0.09 & 0.23 & 0.68 \\
\hline MM\#Race & MM\#White & -0.27 & 0.55 & 0.62 \\
\hline $\begin{array}{l}\text { MM\#Working } \\
\text { Condition }\end{array}$ & MM\#In work & 0.20 & 0.35 & 0.56 \\
\hline MM\#Urbanicity & MM\#Urban & -0.04 & 0.35 & 0.91 \\
\hline MM\#Webuser & MM\#Yes & -0.22 & 0.42 & 0.61 \\
\hline MM\#Email given & MM\#Yes & -0.08 & 0.33 & 0.82 \\
\hline \multirow[t]{6}{*}{ MM\#Age } & MM\#16-20 & 0.65 & 0.62 & 0.30 \\
\hline & MM\#21-30 & 0.22 & 0.63 & 0.73 \\
\hline & MM\#31-40 & -0.53 & 0.46 & 0.26 \\
\hline & MM\#51-60 & 0.14 & 0.47 & 0.77 \\
\hline & MM\#61-70 & -0.71 & 0.53 & 0.18 \\
\hline & MM\#71+ & 0.30 & 0.52 & 0.56 \\
\hline \multirow[t]{3}{*}{ MM\#Household type } & MM\#Single & -0.20 & 0.44 & 0.66 \\
\hline & MM\#Single, children & -0.44 & 0.67 & 0.51 \\
\hline & MM\#Couple, children & -0.71 & 0.52 & 0.18 \\
\hline
\end{tabular}


Table 4. Continued.

\begin{tabular}{llccc}
\hline Variable & Category & Coefficient & Std. Error & $P$-value \\
\hline & $\begin{array}{l}\text { MM\#2+ unrelated } \\
\text { adults } \\
\text { MM\#2+ unrelated } \\
\text { adults, children }\end{array}$ & -0.62 & 0.53 & 0.25 \\
MM\#Web preference & $\begin{array}{l}\text { MM\#Maybe } \\
\text { MM\#Yes }\end{array}$ & 0.84 & 0.42 & 0.12 \\
& & 1.09 & 0.45 & $\mathbf{0 . 0 5}$ \\
\hline
\end{tabular}

The Nagelkerke $\mathrm{R}^{2}$ is 0.119 .

To answer the first research question on participation rates (RQ1), the mixed-mode design does not affect individual participation either overall or amongst those who have been in the panel for longer or shorter periods. The mixed-mode design appears to have a positive effect for those who had not responded at Wave 4, though statistical significance is borderline. As for other subgroups, which had been identified to be less likely to give an interview at Wave 5 in Jäckle et al. (2015), only expressed preference to respond by web showed to have a positive effect on participation in the mixed-mode group with respect to the primarily face-to-face group. No other difference between mode treatments was found.

\subsection{Household Participation}

For households, we analyse outcomes for each wave separately, since a concept of longitudinal household does not make sense as household composition and location may change over time.

The proportion of households participating in the original sample (Table 5) did not differ significantly between treatments in Wave $5(P=0.22)$ or Wave $6(P=0.79)$, while the mixed-mode design resulted in a 6.5 percentage point higher participation rate than face-to-face in Wave $7(P=0.03)$. As for the proportion of complete households, in the original sample it is 7.1 percentage points lower $(P=0.03)$ with the mixed-mode design than with face-to-face only in Wave 5, and by Wave 7 it becomes 10.5 points higher $(P=0.00)$. Non-contacts and refusals in the mixed-mode group are higher than in the face-to-face group in Wave $5(P=0.08)$, not significantly different in Wave 6 $(P=0.33$ and $P=0.89$. respectively), and lower in Wave $7(P=0.07$ and $P=0.06$, respectively).

These effects differ between previous wave respondents and nonrespondents. Amongst previous wave responding households in the original sample, the proportion of refusals with the mixed-mode treatment compared with face-to-face was higher at Wave $5(12.4 \%$ vs. $6.9 \%, P=0.03)$, not different at Wave $6(P=0.60)$, and lower at Wave $7(7.2 \%$ vs. $11.2 \%, P=0.03)$. No statistically significant differences are observed for previous wave nonrespondents in the original sample.

For those who have entered the panel more recently (refreshment sample), no statistically significant difference between the mode treatment groups was observed in any wave with respect to household participation and complete household participation (results not shown). 


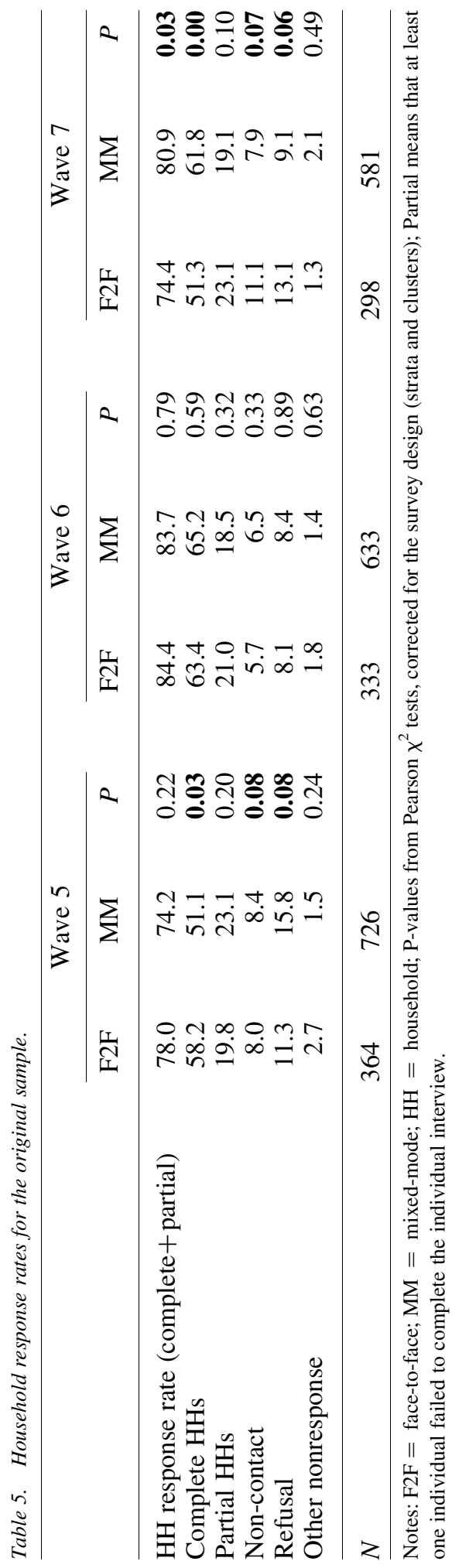




\section{Sample Composition}

In this section, we explore whether the two different mode treatments had different effects on sample composition (RQ2). More precisely, we investigate whether there is a mode difference in whether sample composition at each wave and, especially, in the sample that responded at all three waves, differs from the composition at the start of the experiment. We test this assumption by comparing the distribution of covariates collected at Wave 4 (or last wave interview before Wave 5) for different subgroups of respondents. The statistical test for differences in sample composition with respect to a variable is performed by fitting a logistic regression model predicting response in which predictors are mode treatment, the variable under consideration, and the interaction between mode and the variable. The Wald test on the interaction coefficients is a test of whether the association between the outcome and the variable differs by mode. We consider different groups of respondents: individuals responding at Wave 5, individuals responding at Waves 5 and 6 , and individuals responding at Waves 5, 6, and 7 .

The variables that we considered are those where we expect the greatest chance of a mode difference, on the basis of results in previous studies. More precisely, we consider variables found to be related to response behaviour at Wave 5 in Jäckle et al. (2015, Tables 8 and 9). All these variables are related to at least some substantive variable of interest. For example, ethnicity is an important predictor in studies on social inequalities (Wallace et al. 2016; Chng et al. 2016), while urbanicity figures prominently in research on commuting effects (Evandrou et al. 2016). Therefore any effect of nonresponse on sample composition in respect of these variables has the potential to introduce bias in substantive estimates of interest to researchers.

Results are shown in Table 6. For respondents at Wave 5, only household type shows a significant difference between the mixed-mode and face-to-face group $(P=0.04)$. As for respondents at Waves 5 and 6 and respondents at all three waves, the only variable showing a mode difference in how sample composition differs from the composition at the start of the experiment is expressed web preference ( $P=0.06$ and $P=0.08$, respectively). The proportion of respondents who said at Wave 4 that they definitely would not respond to a web survey decreases by 2.6 percentage points in the mixed-mode group for respondents at all three waves with respect to the initial sample, while it increases by 1.6 percentage points in the face-to-face group.

Overall, and to answer the second research question (RQ2), we conclude that differences between the two treatment groups in sample composition are minimal.

\section{Costs}

As stated earlier, one of the main reasons for the use of web in a mixed-mode design is to save costs. In this section we provide an indication of the scale of the data collection cost differential between the two mode treatments (RQ3). The estimate can only be indicative as the realised cost saving from a mixed-mode design such as this one in any particular situation will depend on several aspects of the survey context, survey design, and contractual and remuneration arrangements. Furthermore, focusing solely on data collection costs ignores the possibility that a survey agency might incur initial setup costs 


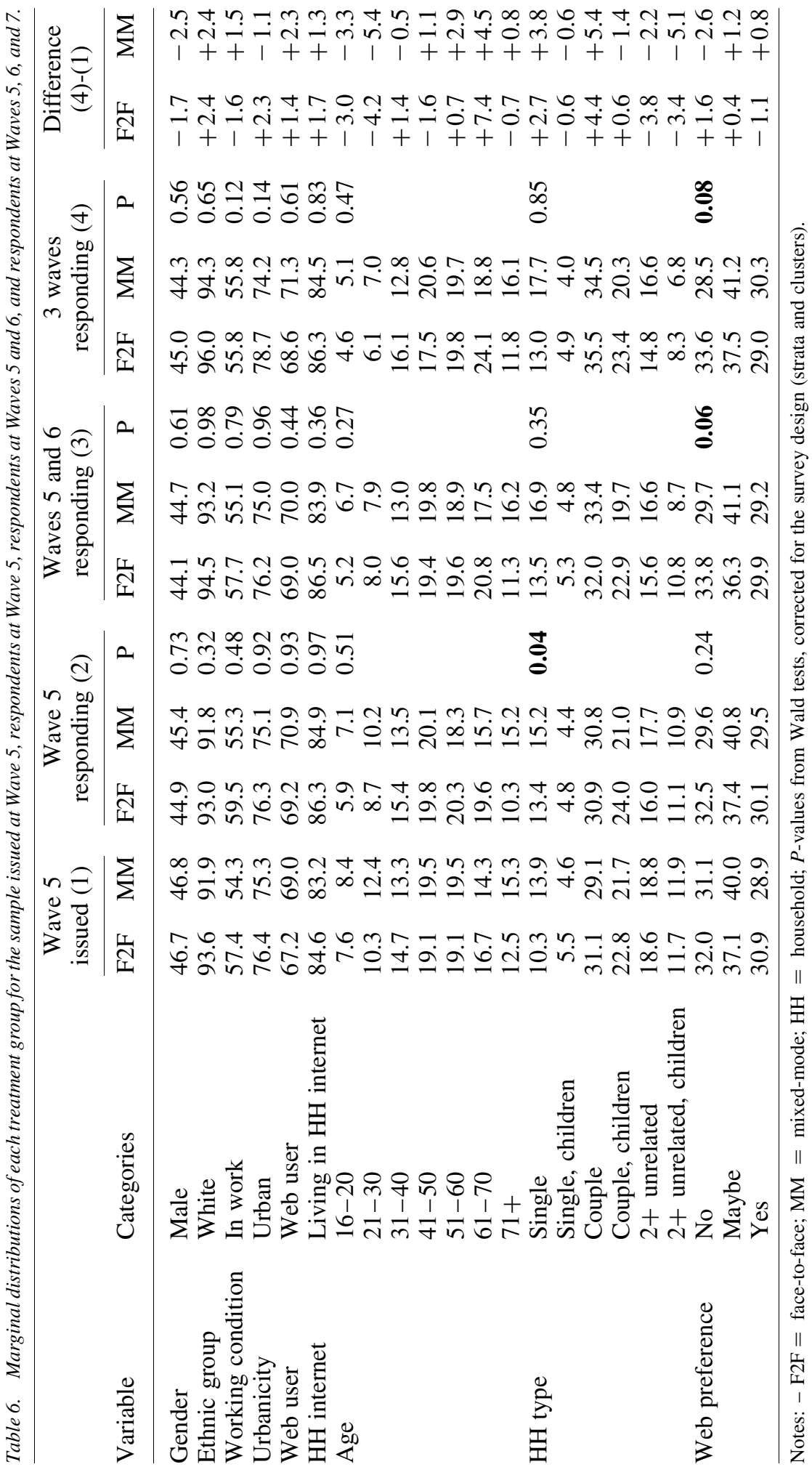


in introducing a mixed-mode system, and that the cost of some office-based tasks may be greater for a mixed-mode survey. Despite these limitations, the analysis presented here may give a useful impression of the scale of cost-savings with a mixed-mode design.

The main driver of the difference in data collection costs between the two mode treatments is the fact that some sample households do not require an interviewer visit in the mixed-mode treatment. The proportion of households fully responding by web can therefore be used as an initial indicator of potential cost savings, as a full response by web negates the need to send an interviewer to visit the household. The proportion of fully responding households who fully responded by web increased over time, from $42.7 \%$ in Wave 5 to $57.5 \%$ in Wave 7 (Table 7). This increase over time is apparent for both the original sample (previous wave respondents) and the refreshment sample (results not shown), though at every wave the proportion of households fully responding by web is higher in the refreshment sample than in the original sample. For example, at Wave 7 the proportion of fully-responding households who fully responded by web was $56 \%$ in the original sample, compared to $72 \%$ in the refreshment sample. It is noteworthy that in Waves 6 and 7 more than one-third of all households fully responded by web $(37.1 \%$ and $35.1 \%$, respectively).

If field costs per issued sample household - excluding the cost of incentives - were assumed to be approximately GBP 110 with the primarily face-to-face treatment, and GBP 5 per household for the web phase of the mixed-mode treatment, this would imply that costs in the mixed-mode design would be around GBP 5 for each household that fully responds by web and GBP 115 for each other household. Applying these unit costs to the response outcomes in Table 7 would imply that the mixed-mode design could bring about reductions in the cost per household issued to the field of around $19 \%$ at Wave 5, 33\% at Wave 6 and $31 \%$ at Wave 7 (Table 8, rows 2 and 5). However, these figures do not include the costs of incentives which, for Waves 6 and 7, were higher in the mixed-mode treatment group. Rows 1 and 4 of Table 8 show the mean cost of incentives per issued household in each mode for each wave, taking into account the proportion of households in the mixedmode sample that qualified for the conditional incentives, as well as all unconditional incentives. Incorporating these into the overall data collection costs (rows 3 and 6), the cost differential between mode treatments reduces, with the result that the mixed-mode design is now estimated to bring cost savings of around 15\% at Wave 5, 8\% at Wave 6 and

Table 7. Proportion of households fully responding by web and proportion of households fully responding at waves 5, 6, and 7 .

\begin{tabular}{lccc}
\hline & Wave 5 & Wave 6 & Wave 7 \\
\hline Mixed-mode sample & & & \\
\% fully responding by web (A) & 23.8 & 37.1 & 35.1 \\
$\%$ fully responding (B) & 55.7 & 66.7 & 61.0 \\
$(\mathrm{~A}) /(\mathrm{B})$ & 42.7 & 55.6 & 57.5 \\
$N$ & 1,041 & 925 & 846 \\
\hline Face-to-face sample & & & \\
$\%$ fully responding & 58.8 & 62.8 & 52.8 \\
$N$ & 532 & 498 & 451 \\
\hline
\end{tabular}


Table 8. Mean field cost per issued household for each treatment group and for each wave.

\begin{tabular}{lrrr}
\hline & Wave 5 (GBP) & Wave 6 (GBP) & Wave 7 (GBP) \\
\hline Mixed-mode treatment & & & \\
Incentives & 29.74 & 49.35 & 41.91 \\
Other & 88.82 & 74.19 & 76.39 \\
Total & 118.56 & 123.54 & 118.30 \\
\hline Face-to-face treatment & & & \\
$\quad$ Incentives & 29.70 & 24.58 & 22.77 \\
$\quad$ Other & 110.00 & 110.00 & 110.00 \\
Total & 139.70 & 134.58 & 132.77 \\
\hline
\end{tabular}

$11 \%$ at Wave 7 . It should be noted, however, that these estimated cost savings may have limited generalisability as realised savings will depend on factors such as the cluster sample size, the geographical dispersion of sample addresses within the cluster, and whether interviewers are remunerated equally for interviewing a web-nonrespondent household as they would have been for interviewing a household in a simple face-to-face survey.

\section{Conclusions}

Regarding possible effects of the mixed-mode design on response rates, either overall or amongst important subgroups (RQ1), for individual participation no difference between mode treatments was detected overall (both cumulative response rate and response rate in each wave). Also, no differences were found in either the original sample or the refreshment sample as a whole, while the mixed-mode design performed slightly better amongst previous wave nonrespondents in the original sample. As for covariates, only expressed mode preference has been found to be related to participation in the mixedmode group rather than in the primarily face-to-face group. These are very useful results with respect to the implementation of a mixed-mode design with web in a longitudinal survey. They suggest that such a design should not damage participation rates over several waves and may even improve participation amongst sample members who are otherwise less likely to participate. The finding regarding expressed mode preference suggests that answers to a question such as this could usefully be taken into account as part of a strategy for targeted allocation of sample members to mode treatments (Lynn 2014).

As for household participation, no differences could be found in Wave 5 and Wave 6 overall, but the mixed-mode design showed a better performance than face-to-face in Wave 7: higher household participation, higher complete household interviews, and lower non-contact rates. For those who had entered the panel more recently (refreshment sample), no difference in household participation could be detected in any of the three waves. For those who had been longer in the panel (original sample), the mixed-mode design resulted in smaller proportion of households fully responding and higher proportion of non-contacts and refusals in Wave 5; in Wave 7, the situation was completely reversed.

With respect to possible effects of the mixed-mode design on sample composition (RQ2), differences between the two treatment groups in sample composition are minimal. The data provide little evidence of mode treatment affecting sample composition. 
With regard to possible cost savings related to the use of the web in the mixed-mode design (RQ3), the mixed-mode design appears to have potential to deliver substantial cost savings. At both Waves 6 and 7, more than one-third of households issued to the field fully responded by web. Our estimates suggest possible field cost savings per issued household in the region of ten percent, compared to face-to-face. The extent to which this saving would be realised in practice depends on, amongst other things, whether the amount of field effort required per household amongst the two-thirds of mixed-mode households that need to be issued to a face-to-face interviewer differs from that amongst the face-to-face sample. Analysis of call record data (results not shown) suggests that in this study the mean number of interviewer visits to a sample household was actually lower in the mixedmode group (amongst households issued to a face-to-face interviewer) than in the primarily face-to-face group. This suggests that the indicated cost savings could well be fully realised.

\section{Discussion}

The introduction of web-face-to-face sequential mixed-mode data collection as a costsaving alternative to single-mode face-to-face has been considered by many surveys but has generally been treated with caution due to concerns about possible negative impacts on nonresponse and measurement. This article has not considered measurement issues, but with regard to nonresponse we suggest that the concerns seem largely unwarranted, at least in the context of an ongoing panel survey. We have found no differences between the mixed-mode and primarily face-to-face designs in cumulative response rates over three waves of the panel, nor were significant differences found in the composition of the responding sample. Meanwhile, the potential for worthwhile field cost savings is evidenced by the sizeable proportion of sample households in which all adult members completed the questionnaire by web. This study therefore paints a rather positive picture of the potential for mixed-mode data collection in panel surveys.

However, some unresolved issues remain. Not least amongst them is the question of whether, and in what circumstances, measurement can be considered to be equivalent between the modes. The considerable literature on mode effects suggests that certain question characteristics tend to be associated with measurement differences between modes, particularly between self-completion and interviewer-administered modes (Couper 2011; de Leeuw 2005; Krosnick and Alwin 1987; Schwarz et al. 1991). For any particular survey considering the introduction of a mixed-mode design, the questionnaire content could be reviewed in the context of this literature, while effects on nonresponse error could be considered in the context of the findings of the current study, thus contributing to an overall evaluation of total survey error.

That said, it would be reasonable to question whether our findings would apply in different survey contexts (different topics of questioning, different study populations, different levels of prior survey engagement, etc.). Sensitivity to context is of course possible. However, we can draw some strength from that fact that our findings were broadly similar for the two different samples involved and for several demographic subgroups. The former suggests that our broad conclusions apply equally to sample members with only one previous wave and to those with four previous interviewer-administered waves, and 
therefore that the degree of prior survey engagement does not have a strong influence on the outcomes studied. The latter suggests that the results might equally apply to study populations with rather different demographic profiles. Taken together, these findings provide some indication that our conclusions are at least somewhat robust.

\section{References}

Bianchi, A. and S. Biffignandi. 2014. "Responsive Design for Economic Data in MixedMode Panels." In Contribution to Sampling Statistics, edited by F. Mecatti, P.L. Conti, and M.G. Ranalli, 85-102. Springer International Publishing.

Bianchi, A. and S. Biffignandi. 2017. "Representativeness in Panel Surveys." To appear in Mathematical Population Studies.

Bianchi, A. and S. Biffignandi. Forthcoming. "Survey Experiments on Interactions: a Case Study of Incentives and Modes." In Experimental Methods in Survey Research: Techniques that Combine Random Sampling with Random Assignment, edited by P.J. Lavrakas, E. de Leeuw, A. Holbrook, C. Kennedy, M.W. Traugott, and B.T. West. Hoboken NJ: John Wiley \& Sons.

Biemer, P.P. 2010. “Total Survey Error: Design, Implementation and Evaluation.” Public Opinion Quarterly 74(5): 817-848. Doi: http://dx.doi.org/10.1093/poq/nfq058.

Biemer, P.P. and L.E. Lyberg. 2003. Introduction to Survey Quality. New York: John Wiley.

Bowling, A. 2005. "Mode of Questionnaire Administration Can Have Serious Effects on Data Quality." Journal of Public Health 27: 281-291.

Buck, N. and S. McFall. 2012. "Understanding Society: Design Overview." Longitudinal and Life Course Studies 3: 5-17.

Calinescu, M. and B. Schouten. 2015. "Adaptive Survey Designs to Minimize Survey Mode Effects - a Case Study on the Dutch Labor Force Survey." Survey Methodology 41(2) : 403-425.

Chng, S., M. White, C. Abraham, and S. Skippon. 2016. "Commuting and Wellbeing in London: the Roles of Commute Mode and Local Public Transport Connectivity." Preventive Medicine 88: 182-188. Doi: http://dx.doi.org/10.1016/j.ypmed.2016. 04.014.

Couper, M. 2011. "The Future of Modes of Data Collection.” Public Opinion Quarterly 75: 889-908. Doi: http://dx.doi.org/10.1093/poq/nfr046.

Evandrou, M., J. Falkingham, Z. Feng, and A. Vlachantoni. 2016. "Ethnic Inequalities in Limiting Health and Self-Reported Health in Later Life Revisited." Journal of Epidemiology \& Community Health 70: 653-662. Doi: http://dx.doi.org/10.1136/ jech-2015-206074.

Fan, W. and Z. Yan. 2010. "Factors Affecting Response Rates of the Web Surveys: a Systematic Review." Computers in Human Behavior 26: 132-139.

Farrant, G. and C. O’Muircheartaigh. 1991. "Components of Nonresponse Bias in the British Election Surveys." In Understanding Political Change, edited by A. Heath, J. Curtice, R. Jowell, S. Evans, J. Field, and S. Witherspoon, 235-249. London: Pergamon Press. 
Fong, B. and J. Williams. 2011. "British Crime Survey: Feasibility of Boosting Police Force Area (PFA) Sample Sizes Using Supplementary Recontact Surveys.” Report for the Home Office, TNS-BMRB, London.

Gaia, A. 2014. "Does a Mixed-Mode Design Increase Panel Attrition? Evidence from the UKHLS Innovation Panel." Paper presented at the Internet Survey Methodology Workshop, Bolzano, December 1-3.

Göritz, A. 2006. "Incentives in Web Studies: Methodological Issues and a Review." International Journal of Internet Science 1: 58-70.

Göritz, A. 2010. "Using Lotteries, Loyalty Points, and Other Incentives to Increase Participant Response and Completion." In Advanced methods for conducting online behavioural research, edited by S. Gosling and J. Johnson, 219-233. Washington DC: American Psychological Association. Doi: http://dx.doi.org/10.1037/12076-014.

Göritz, A. 2015. “Incentive Effects.” In Improving Survey Methods: Lessons from Recent Research, edited by U. Engel, B. Jann, P. Lynn, A. Scherpenzeel, and P. Sturgis, 339-350. London: Routledge.

Griffin, D., D. Fischer, and M. Morgan. 2001. "Testing an Internet Response Option for the American Community Survey." Paper presented at the annual conference of the American Association for Public Opinion Research Montreal." Quebec, Canada, May 17-20.

Groves, R. and L. Lyberg. 2010. “Total Survey Error: Past, Present, and Future.” Public Opinion Quarterly 74(5): 849-879. Doi: http://dx.doi.org/10.1093/poq/nfq065.

Groves, R.M. and F. Peytcheva. 2008. "The Impact of Nonresponse Rates on Nonresponse Bias: A Meta-Analysis." Public Opinion Quarterly 72: 167-189. Doi: https://doi.org/10.1093/poq/nfn011.

Jäckle, A. 2016. "Mode Effects on Measurement in Understanding Society." Paper presented at the International Panel Survey Methods Workshop, Berlin, June 20-21. Available at: http://www.diw.de/en/diw_01.c.534396.en/program_psmw2016.html (accessed March 2017).

Jäckle, A. and P. Lynn. 2008. "Respondent Incentives in a Multi-Mode Panel Survey: Cumulative Effects on Nonresponse and Bias.” Survey Methodology 34: 105-117.

Jäckle, A., P. Lynn, and J. Burton. 2015. "Going Online with a Face-to-Face Household Panel: Effects of a Mixed Mode Design on Item and Unit Non-Response." Survey Research Methods 9(1): 57-70. Doi: http://dx.doi.org/10.18148/srm/2015.v9i1.5475.

Janssen, B. 2006. "Web Data Collection in a Mixed Mode Approach: An Experiment." Paper presented at the European Conference on Quality in Official Statistics (Q2006), Cardiff, April 24-26. Available at: webarchive.nationalarchives.gov.uk/ 20140721132900/http://ons.gov.uk/about/newsroom/events/q2006-european-conference-on-quality-in-survey-statistics-24-26-april-2006/agenda/session-19-wednesday.pdf (accessed March 2017).

Klausch, T., J. Hox, and B. Schouten. 2015a. "Selection Error in Single- and Mixed Mode Surveys of the Dutch General Population.” Journal of the Royal Statistical Society, Series A 178(4): 945-961. Doi: http://dx.doi.org/10.1111/rssa.12102.

Klausch, T., B. Schouten, and J.J. Hox. 2015b. "Evaluating Bias of Sequential Mixedmode Designs Against Benchmark Surveys.” Sociological Methods \& Research : 1-34. Doi: http://dx.doi.org/10.1177/0049124115585362. 
Kreuter, F. 2013. "Facing the Nonresponse Challenge." The Annals of the American Academy of Political and Social Science 645: 23-35. Doi: https://doi.org/ 10.1177/0002716212456815.

Krosnick, J.A. and D.F. Alwin. 1987. “An Evaluation of a Cognitive Theory of ResponseOrder Effects in Survey Measurement." Public Opinion Quarterly 51: 201-219. Doi: https://doi.org/10.1086/269029.

Lagerstrøm, B. 2008. "Cost Efficiency in a Mixed-Mode Survey - Evidence from the Norwegian Rent Market Survey.” Paper presented at the 19th International Workshop on Household Survey Nonresponse, Ljubljana, September 15. Available at: http://www.nonresponse.org/db/3/558/Biblliography/Cost\%20efficiency\%20in\%20a\% 20 mixed-mode $\% 20$ survey $\% 20$ Evidence $\% 20$ from $\% 20$ the $\% 20$ Norwegian $\% 20$ Rent \%20Marked\%20Survey/?\&p1=308\&p2=74\&p3=551 (accessed March 2017).

Laurie, H. and P. Lynn. 2009. "The Use of Respondent Incentives on Longitudinal Surveys." In Methodology of Longitudinal Surveys, edited by P. Lynn, 205-233. Chichester: Wiley.

Leesti, T. 2010. "Canadian Labour Force Survey Internet Data Collection Pilot Test." Paper presented at the Fifth Workshop on Labour Force Survey Methodology, Paris, April 15-16.

De Leeuw, E.D. 2005. “To Mix or not to Mix Data Collection in Surveys." Journal of Official Statistics 21: 233-255.

Lugtig, P. 2014. "Panel Attrition: Separating Stayers, Fast Attriters, Gradual Attriters, and Lurkers.” Sociological Methods and Research 43(4): 699-723. Doi: http://dx.doi.org/ 10.1177/0049124113520305.

Lynn, P. 2009. "Sample Design for Understanding Society." Understanding Society Working Paper 2009-01, ISER, University of Essex, Colchester. Available at: www.understandingsociety.ac.uk/research/publications/working-paper/understandingsociety/2009-01 (accessed 16 March 2017).

Lynn, P. 2013. "Alternative Sequential Mixed-Mode Designs: Effects on Attrition Rates, Attrition Bias and Costs.” Journal of Survey Statistics and Methodology 1: 183-205. Doi: http://dx.doi.org/10.1093/jssam/smt015.

Lynn, P. 2014. “Targeted Response Inducement Strategies on Longitudinal Surveys.” In Improving Survey Methods: Lessons from Recent Research, edited by U. Engel, B. Jann, P. Lynn, A. Scherpenzeel, and P. Sturgis. Routledge/Psychology Press.

Lynn, P. Forthcoming. "Tackling Panel Attrition.” In The Palgrave Handbook of Survey Research, edited by D.L. Vannette and J.A. Krosnick. Palgrave.

Lynn, P. and A. Jäckle. Forthcoming. "Mounting Multiple Experiments on Longitudinal Social Surveys: Design and Implementation Considerations.” In Experimental Methods in Survey Research: Techniques that Combine Random Sampling with Random Assignment, edited by P.J. Lavrakas, E.E. de Leeuw, A. Holbrook, C. Kennedy, M.W. Traugott, and B.T. West. Hoboken NJ: Wiley.

Lynn, P. and P. Lugtig. 2017. "Total Survey Error for Longitudinal Surveys.” In Total Survey Error in Practice, edited by Paul Biemer, Edith de Leeuw, Stephanie Eckman, Brad Edwards, Frauke Kreuter, Lars Lyberg, Clyde Tucker, and Brady West, 279-298. Hoboken, New Jersey: Wiley. 
Lynn, P. and D. Lievesley. 1991. "Drawing General Population Samples in Great Britain." London: SCPR.

Lynn, P. S.C.N. Uhrig, and J. Burton. 2010. "Lessons from a Randomized Experiment with Mixed-Mode Designs for a Household Panel Survey." Understanding Society, Working Paper Series, 2010-03.

Martin, P. and P. Lynn. 2011. "The Effects of Mixed Mode Survey Designs on Simple and Complex Analyses.” ISER Working Paper Series, 2011-28. Colchester: Institute for Social and Economic Research, University of Essex. Available at: https://www.iser. essex.ac.uk/research/publications/working-papers/iser/2011-28 (accessed February 5, 2013).

Schoeni, R., F. Stafford, K. McGonagle, and P. Andreski. 2013. "Response Rates in National Panel Surveys." The Annals of the American Academy of Political and Social Science 645: 60-87. Doi: https://doi.org/10.1177/0002716212456363.

Schwarz, N., F. Strack, H.-J. Hippler, and G. Bishop. 1991. "The Impact of Administration Mode on Response Effects in Survey Measurement." Applied Cognitive Psychology 5: $193-212$.

Souren, M. 2012. "Multi-Mode Surveys at Statistics Netherlands: Implications, Experiences and Open Issues." Paper presented at Opening Conference of the European Statistical System Network (ESSNet) on Data Collection for Social Surveys using Multiple Modes, Wiesbaden, October 11-12, 2012.

Uhrig, S.C.N. 2008. "The Nature and Causes of Attrition in the British Household Panel Study." Institute for Social and Economic Research Working Paper 2008-05. Available at: https://www.iser.essex.ac.uk/research/publications/working-papers/iser/2008-05 (accessed 16 March 2017).

Uhrig, S.C.N. 2011. "Using Experiments to Guide Decision Making in Understanding Society: Introducing the Innovation Panel.” In Understanding Society: Early Findings from the First Wave of the UK's Household Longitudinal Study, edited by S.L. McFall and C. Garrington. Colchester: University of Essex. Available at: http://research. understandingsociety.org.uk/findings/early-findings (accessed 16 March 2017).

Voogt, R. and W. Saris. 2005. "Mixed Mode Designs: Finding the Balance between Nonresponse Bias and Mode Effects." Journal of Official Statistics 21(3): 367-387.

Voorpostel, M. and V.A. Ryser. 2011. "Mixed Mode Data Collection as a Strategy to Decrease Panel Attrition in the Swiss Household Panel.” FORS Working Paper 2_11. Available at: http://ohs-shp.unil.ch/workingpapers/WP2_11.pdf (accessed 28 March 2017).

Wallace, S., J. Nazroo, and L. Bécares. 2016. "Cumulative Effect of Racial Discrimination on the Mental Health of Ethnic Minorities in the United Kingdom." American Journal of Public Health 106(7): 1294-1300. Doi: http://dx.doi.org/10.2105/AJPH.2016.303121.

Watson, N. and M. Wooden. 2014. "Re-Engaging with Survey Non-Respondents: Evidence from Three Household Panels." Journal of the Royal Statistical Society Series A (Statistics in Society) 177(2): 499-522. Doi: http://dx.doi.org/10.1111/rssa.12024.

Received February 2016

Revised December 2016

Accepted January 2017 